\title{
O Recife da Cidade: representações de uma paisagem fundacional em artefatos gráficos do acervo cartográfico do Museu da Cidade do Recife
} The 'recife' (reef) of the city: representations of a founding landscape in graphic artefacts from the cartographic collection at the Museum of the City of Recife

\author{
Josivan Rodrigues \& Solange Coutinho
}

representações visuais, artefatos gráficos, imagem do Recife, paisagem, cartografia

\begin{abstract}
Este artigo investiga as representações gráficas do acidente geográfico que dá nome à cidade do Recife, Pernambuco/Brasil, presentes no acervo do Museu da Cidade do Recife - MCR. O vocábulo arrecife, sinônimo para recife, tem sua origem etimológica no termo árabe "ár-racif", que significa calçada sobre as águas, caminho, cais, molhe. $\mathrm{O}$ ancoradouro natural definido pelos arrecifes converte o "Recife dos Navios" em uma nova centralidade a partir das atividades portuárias, trazendo o desenvolvimento para 0 minúsculo povoado que se tornaria capital da província no século XIX. Considerando a paisagem dos arrecifes enquanto elemento fundacional da cidade (Gonçalves et al., 2017), no que pesa sua importância para o estabelecimento e desenvolvimento da urbe, buscou-se entender os aspectos materiais e simbólicos desta estrutura híbrida, formada pela natureza e modelada pela ação humana, para analisar suas representações visuais no corpus documental Cartografia, composto por artefatos gráficos que mostram a evolução da cidade, do fazer cartográfico e da produção gráfica, ao passo em que apresentam as mudanças na feição do acidente geográfico e em suas representações. A análise se deteve em maior profundidade no subconjunto de Mapas e Cartas, a partir de quatro espécimes representativos de plantas da cidade, produzidas entre os séculos XVII e XX.
\end{abstract}

visual representations; graphic artefacts; image of Recife; landscape; cartography

This paper investigates graphic representations of the geographical accident that has given its name to the city of Recife, in Pernambuco, Brazil, found in the collection of the Museum of the City of Recife - MCR. The Portuguese - word arrecife, meaning 'reef', originates from the Arabic term "ár-racif", which signifies paved on the water, a pathway, a pier, a jetty. The natural anchorage defined by the reefs converted the "Recife of Ships" into a new centrality because of its port activities, thereby bringing development to the tiny settlement, which was to become the provincial capital in the nineteenth century. By considering this landscape of reefs as the founding element of the city (Gonçalves et al., 2017), in what is deemed important for the establishment and development of the city, we have sought to understand the material and symbolic aspects of this hybrid structure, formed by nature and modelled by human action, so as to analyse their visual representations in the corpus of cartographic documentation, composed of graphic artefacts that show the evolution of the city, from the cartographic and graphic production, to presenting the changes resulting from the geographical accident and its representations. The focus of the analysis was aimed towards a subset of maps and charts, from four representative specimens of the city plans, produced between the seventeenth and twentieth centuries.

\section{Um cinturão de pedras, um porto, uma cidade}

A cidade do Recife traz em seu topônimo a referência à cinta de pedras que acompanha a sua costa. O vocábulo arrecife, sinônimo para recife, tem sua origem etimológica no termo árabe "ár-racif", que significa calçada sobre as águas, caminho, cais, molhe (Silva, como citado em Fonseca, 2009), também denominado por arenito, arenito praial, rocha praial, beachrock etc. Estruturas comuns em toda a costa do Nordeste brasileiro, sobretudo nas desembocaduras de rios, constituem um traço fisiográfico da região (Branner, 1904; Barreto et al., 2010).

\author{
Anais do 9 CIDI e 9 CONGIC \\ Luciane Maria Fadel, Carla Spinillo, Anderson Horta, \\ Cristina Portugal (orgs.) \\ Sociedade Brasileira de Design da Informação - SBDI \\ Belo Horizonte | Brasil | 2019 \\ ISBN 978-85-212-1728-2
}

Proceedings of the 9th CIDI and 9th CONGIC Luciane Maria Fadel, Carla Spinillo, Anderson Horta, Cristina Portugal (orgs.)

Sociedade Brasileira de Design da Informação - SBDI Belo Horizonte | Brazil | 2019

ISBN 978-85-212-1728-2 
De acordo com Barreto et al. (2010), são importantes testemunhos dos níveis mais altos do mar no passado e são formados a partir da reação do carbonato de cálcio, presente na água do mar, em contato com o lodo trazido pelos rios que petrificam as linhas de praia, ao longo de um processo de milhares de anos. Por sua vez, Josué de Castro (1959), coloca o papel fundamental dessa rocha praial para a formação do solo da cidade. Junto a outros fatores responsáveis pela formação da planície aluvional, esta "baía entulhada" na qual foi assentada a cidade do Recife, os arrecifes cumpriram o papel de uma represa:

Esse cordão de pedra, colocado à frente da barra dos rios, ajudou a reter, como uma barragem, os detritos aluvionais acumulados, moderando a ação, porventura demolidora, das vazantes que poderiam arrastar para o mar os depósitos em formação. (Castro, 1959 [2013], p. 33).

Os arrecifes que nomeiam a capital pernambucana possuem uma estrutura linear com 10 $\mathrm{km}$ de extensão e uma largura média de $20 \mathrm{~m}$. Está dividido em dois segmentos definidos pela erosão marítima e pela atividade antrópica de retirada de pedras para construções militares e civis $^{1}$. O trecho norte está situado entre a Entrada da Barra do porto e a parte norte do bairro do Pina, possui $6 \mathrm{~km}$ de comprimento e se mantém exposto mesmo durante a maré alta. $\mathrm{Da}$ extremidade norte do bairro do Pina até às imediações da Praça da Igreja de Nossa Senhora da Boa Viagem, no bairro de mesmo nome, o segundo trecho compreende $4 \mathrm{~km}$ de extensão, sendo visível apenas nas marés baixas, quando se formam piscinas naturais muito apreciadas pelos banhistas (Barreto et al., 2010).

Na imagem intitulada "Vista em voo de pássaro da 'baía entulhada' de Pernambuco" (figura 1) constante no livro de John Casper Branner (1904), vemos a representação da planície que forma a cidade do Recife, formada pelos depósitos sedimentares trazidos e rasgados pelos rios Beberibe, Capibaribe, Tejipió, Pina e Jordão. Os arrecifes são representados em toda a sua extensão, da entrada da barra até o bairro de boa viagem. A perspectiva traçada pelo geólogo ressalta as características do relevo, abarcando os limites da planície aluvional definidos pela foz do Capibaribe e Beberibe e pelos morros que a circundam em semicírculo, desde Prazeres até Olinda (Castro, 1959 [2013]). A ilustração elucida o papel da cinta de pedras em barrar a ação das ondas e represar os depósitos de aluvião, assim como explicita a vocação de porto do sítio.

O "Recife dos Navios", um ancoradouro natural situado à extremidade sul do Istmo de Olinda, fez-se de porto da Cidade Mãe, um dos mais importantes da América nos séculos XVI e XVII. Um arrecife de pedra cuja morfologia propiciou uma barreira para defender da fúria das ondas o poço onde poderiam descansar sossegadas as embarcações, desde os primeiros tempos da colônia, enquanto eram abastecidas com as riquezas do Novo Mundo com destino à Metrópole (Maior \& Silva, 1992).

\footnotetext{
1 Podemos verificar o uso do arenito, por exemplo, em fundações e detalhes arquitetônicos de portas e janelas de edificações do centro histórico da cidade do Recife, como é o caso do próprio Museu da Cidade do Recife.
} 
Rodrigues, J. \& Coutinho, S. G. | O Recife da Cidade: representações de uma paisagem fundacional em artefatos gráficos do acervo cartográfico do Museu da Cidade do Recife

Figura 1: Vista em voo de pássaro da baía entulhada de Pernambuco. (Fonte: Branner, 1904).

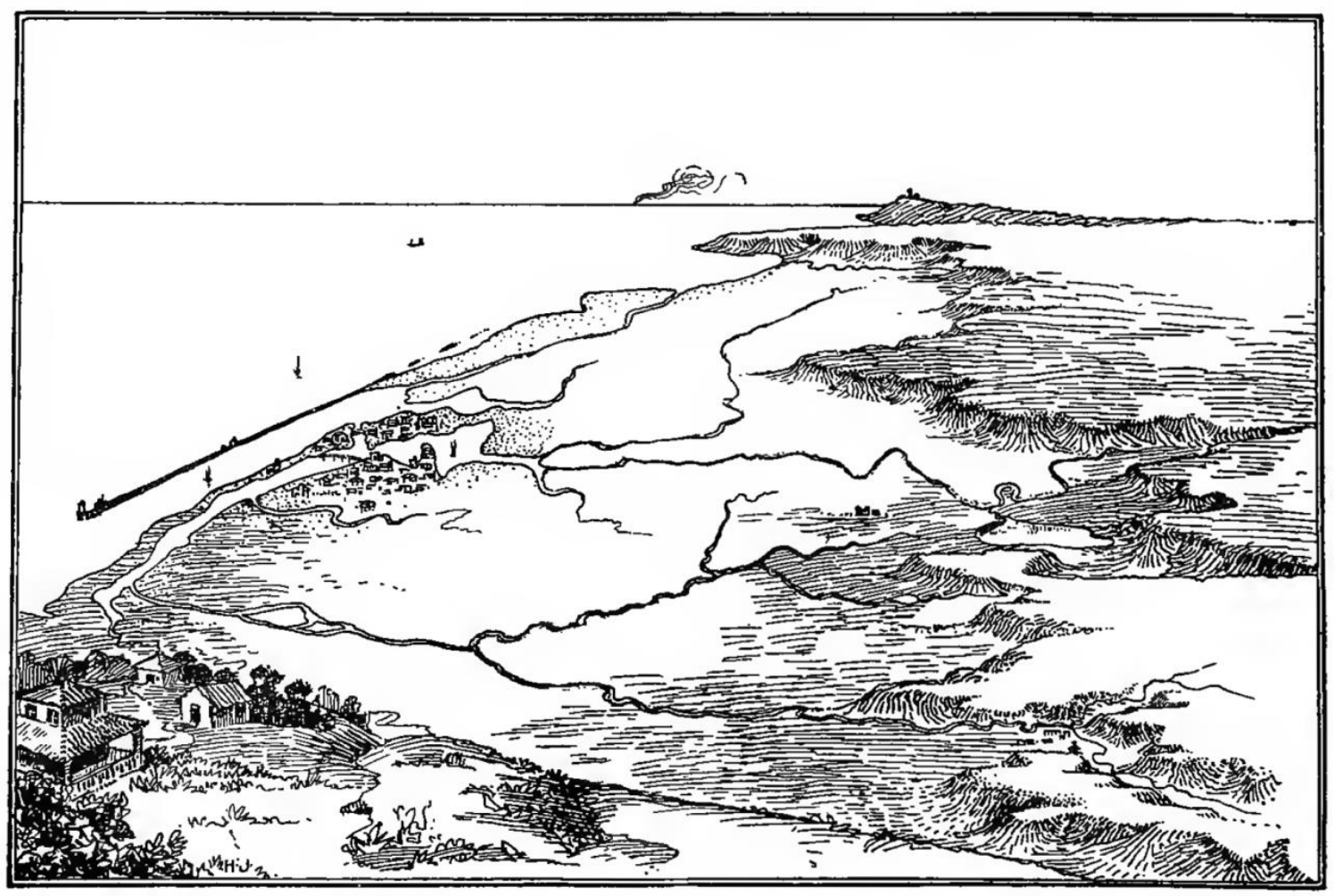

Fig. 75. Bird's-eye view of the Pernambuco embayment.

Primeiro um porto, depois uma cidade que viria a ser modelada, de fato, no século XVII, durante o Domínio Holandês sobre o "Recife de Areia" (Castro, 1959 [2013]), estendendo-se pela Ilha de Antônio Vaz no governo Nassau, a Maurits Stadt. O Recife nunca mais seria o mesmo com a ascensão e o enriquecimento dos comerciantes instalados na "Ribeira do Mar dos Arrecifes dos Navios", chamados de mascates pelos senhores de terras da sede Olinda. O antigo povoado progredira após a expulsão dos holandeses, tornando-se "Vila de Santo Antônio do Recife" em 1709, cidade em 1823, até chegar à capital da província de Pernambuco em 1827 (Maior \& Silva, 1992).

Nesse processo histórico de ocupação e uso do território, caberia entender as transformações pelas quais teria passado a paisagem fundacional da cidade composta pelos arrecifes (Gonçalves et al., 2017), levando em consideração seus aspectos físicos e simbólicos e os desdobramentos presentes em suas representações gráficas, nosso maior interesse.

\section{Paisagem, uma invenção recente}

Embora não seja um espelho cristalino de uma dada cultura, como nos lembra Claval citado por Da Silva (2007), constitui a paisagem um "quadro em relação ao qual aprendemos a nos orientar, ela fala da sociedade na qual se vive, e das relações que as pessoas aí estabelecem com a natureza", possibilitando entender a sociedade que a molda em seus contornos materiais e imateriais. Para Meneses (2002), a paisagem é um bem indispensável para responder questões de territorialidade e de pertencimento, fundamental na interação com o mundo objetivo. Augustin Berque (idem, 2002), esclarece que "as sociedades organizam seu ambiente em função da interpretação que dele fazem e, reciprocamente, o interpretam em função de sua organização". Investigar, pois, o fenômeno da paisagem é fundamental para 
buscar a compreensão das suas representações ou, melhor, como estas refletiriam a relação sociedade-paisagem.

$A$ invenção é recente, data dos séculos $X V$ e XVI, evoluindo a partir deste período e comportando uma diversidade de sentidos. Surge inicialmente na Itália e nos Países Baixos (Meneses, 2002), onde o termo aparece durante o Renascimento. Paesaggio, em italiano, era a palavra usada para descrever o que o olho capta numa única vista, enquanto a palavra holandesa landschap designaria já uma representação, não um lugar natural, mas aquilo que é emoldurado numa pintura (Da Silva, 2007).

O mundo exterior, não mais codificado e mediado pela religião (Roger, 2000 apud Meneses, 2002), era descortinado, inaugurando-se, então, uma nova visão do espaço, da natureza, com a paisagem sendo $o$ assunto principal. Tais formas de representação da paisagem expunham $o$ advento desta enquanto fenômeno social que começava a ser percebido pela sociedade (idem, 2002). A própria passagem da missão científica e artística de Nassau em Pernambuco deixou um legado de intensa produção de temas não religiosos, com as primeiras paisagens a apresentar o novo continente, sobretudo com a circulação da obra do naturalista Barleus².

A paisagem e sua representação chegam a se confundir dada a relação visceral que a primeira tem com as imagens. Ainda que seja impossível existir uma paisagem sem a presença de um observador, esta não é apenas um conjunto de formas físicas sobre a superfície da crosta terrestre (Meneses, 2002). Além da sua materialidade, há dimensões subjetivas que operam em sua assimilação estética, influenciada por fatores culturais e sociais. As relações que se estabelecem entre a sociedade e o ambiente é o que distinguirá uma paisagem de outras formas similares presentes na superfície da Terra. Ou seja, em determinado momento, as configurações de uma tipologia geográfica se convertem em paisagem para uma certa sociedade.

Um fator importante da apropriação estética da paisagem colocado por Berleant a partir de Meneses (2002) são as condições de legibilidade ou de imaginabilidade da paisagem. O que nos leva a acreditar na existência de paisagens mais ou menos legíveis e imagináveis, sabendo que para ler e construir imagens é preciso acessar o objeto e dominar determinados códigos, observar, vivenciar a paisagem e compreender a sua linguagem.

$\mathrm{Na}$ perspectiva da paisagem dos arrecifes da capital pernambucana, temos algumas características que irão repercutir na sua leitura e imaginabilidade. Seja (a) sua extensão, dificilmente abarcada em um único golpe de vista, o que nos obriga a apreensões parcelares que não dão conta da sua totalidade; (b) suas dimensões, fazendo suas formas confundirem-se com as águas, na dinâmica das marés a qual está submetida; (c) ausência de pontos de observação e fruição, sobretudo a partir da remodelação do porto no início do século XX; (d) descontinuidade do transporte marítimo de passageiros que passaram a utilizar outros meios para acessar a cidade; e, (e) mesmo pela descaracterização da estrutura geológica original que recebeu diversos incrementos, evidenciando as obras realizadas sobre a rocha praial.

Contudo, essas especificidades também explicitam as relações da paisagem dos arrecifes com a forma como é vista e apreendida pela sociedade. As obras construídas sobre e a partir da paisagem natural, contudo, são testemunhos desta interação e possibilitam usos distintos do espaço. Assim, tão importantes quanto a estrutura natural o são as marcas culturais e os vestígios incrustados no objeto, como oportunamente colocado por Braudel (1986, como citado em Meneses, 2002), comparando a paisagem com o corpo humano, "condenada a conservar cicatrizes de feridas antigas". Tais marcas presentes na morfologia da paisagem trarão pistas para entendermos os processos naturais e culturais envolvidos em sua produção (Meneses, 2002).

\footnotetext{
${ }^{2}$ A iconografia produzida em Pernambuco durante a ocupação holandesa pode ser divulgada a partir da publicação "História dos feitos recentemente praticados durante oito anos no Brasil..." fartamente ilustrada de 1647, organizada por Gaspar Barleus sob encomenda do Conde Maurício de Nassau (Maior \& Silva, 1992). A obra de 340 páginas é composta por 56 gravuras.
} 
Os arrecifes constituem, afinal, uma paisagem híbrida, formada por um elemento natural abiótico, ainda que sirva de suporte para organismos marinhos, e pela ação do homem. Uma paisagem natural sobre a qual se dá uma ação cultural, configurando, desta forma, uma paisagem cultural $^{3}$, ligada diretamente à gênese de formação da cidade (Gonçalves et al., 2017). A expressão Paisagem Cultural nos serve para ampliar discussões em torno do tema do patrimônio e de sua preservação. A Constituição do estado de Pernambuco define em seu artigo 205 os arrecifes como área de interesse cultural e ambiental (Barreto et al., 2010), assim como na Constituição Federal de 1988, artigo 216, existe instrumentos de proteção da paisagem, também já previstos no Decreto-lei 25/1937 que institui o Serviço de Patrimônio Histórico e Artístico Nacional e daria origem ao IPHAN (Meneses, 2002).

Os documentos que guardam as representações visuais destas paisagens são, por sua vez, importantes chaves para compreensão das relações sociedade-paisagem, além de valiosos testemunhos da memória gráfica, da história do design, da cartografia e das artes gráficas, oferecendo narrativas que permitem compreender diversos momentos da estrutura social produtora destes artefatos.

\section{Uma paisagem no museu}

O Museu da Cidade do Recife - MCR, criado em 1983, é um equipamento cultural vinculado à Secretaria de Cultura da Prefeitura do Recife e tem por missão preservar e divulgar a memória da formação urbana e cultural da cidade. Está instalado no Forte de São Tiago das Cinco Pontas, no bairro de São José, edificação secular tombada pelo Instituto do Patrimônio Histórico e Artístico Nacional.

A instituição museal possui um importante acervo (Quadro 1) que conta a história e o processo evolutivo da cidade, composta por quatro coleções ${ }^{4}$ :

(a) Cartografia, composta por 1.898 itens, incluindo, além dos mapas, gravuras, cartazes, projetos urbanísticos, arquitetônicos e de mobiliário e imagens aerofotogramétricas;

(b) Fotografia, com mais de 200 mil objetos, incluindo negativos de vidro e de acetato, diapositivos e cópias em papel;

(c) Arqueologia e Objetos Tridimensionais, onde temos 9.875 peças entre azulejaria, cerâmica, rochas, projéteis, vidraçaria, entre outros, muitos dos quais fruto de prospecções arqueológicas realizadas na própria fortaleza; e

(d) Livros e Periódicos, formada por 2.126 títulos, acessíveis na biblioteca do museu.

Este acervo, constituído de forma assistemática, fruto de iniciativas dispersas realizadas por órgãos vinculados à gestão municipal e por meio de doações é explorado sobretudo por pesquisadores da história e do urbanismo e tem sido divulgado pela instituição em mostras de longa duração, em publicações impressas e em produtos e suvenires diversos, disponíveis para venda no museu.

\footnotetext{
3 Paisagem cultural é uma categoria referente a bens que combinam características naturais e culturais definida pela UNESCO em 1992, no Encontro Técnico do Comitê do Patrimônio Mundial, considerado um marco na proteção do patrimônio natural e cultural (Meneses, 2002)

${ }^{4}$ Dados coletados no website da instituição <http://museudacidadedorecife.org/> em 15/01/2019.
} 
Rodrigues, J. \& Coutinho, S. G. | O Recife da Cidade: representações de uma paisagem fundacional em artefatos gráficos do acervo cartográfico do Museu da Cidade do Recife

Quadro 1: Coleções que integram o acervo do Museu da Cidade o Recife - MCR. (Fonte: autor)

\begin{tabular}{l|r} 
Coleção & $\begin{array}{r}\text { Quantidade } \\
\text { de itens }\end{array}$ \\
\hline Cartografia & 1.898 \\
\hline Arqueologia e Objetos Tridimensionais & 9.875 \\
\hline Fotografia & 200.000 \\
\hline Livros e Periódicos & (aproximadamente) \\
\hline
\end{tabular}

A coleção cartográfica do acervo do Museu da Cidade do Recife, Cartografia MCR, foco desta abordagem, revela importantes aspectos da evolução da cidade, sendo um dos conjuntos mais acessados pelos pesquisadores. Os atuais 1.898 itens que a compõem encontram-se catalogados, digitalizados e salvaguardados graças a importantes iniciativas realizadas pela instituição e parceiros nos últimos anos ${ }^{5}$ e se apresenta dividida em oito subconjuntos: (a) Mapas e Cartas; (b) Gravuras; (c) Aerofotogrametria; (d) Projetos urbanísticos; (e) Projetos arquitetônicos; (f) Projetos de mobiliário; (g) Documentos Oficiais; e, (h) Tipografia ${ }^{6}$ (figura 2).

Figura 2: Gráfico apresentando a Coleção Cartografia MCR com seus respectivos subconjuntos. (Fonte: autor).

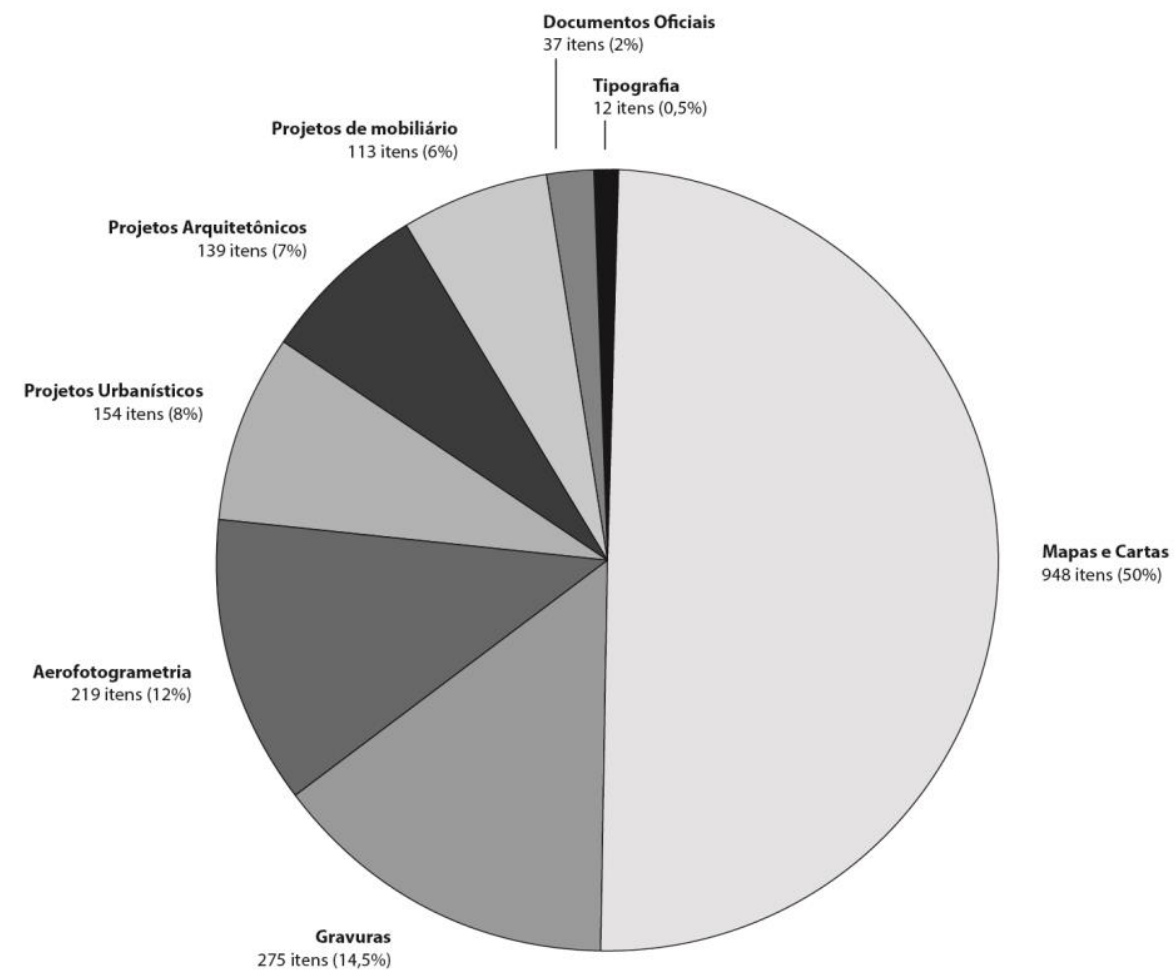

6 (1) Projeto de Preservação e Acesso à Coleção Cartográfica, desenvolvido entre 2005 e 2007 com o incentivo da Caixa Econômica Federal, onde foram realizadas ações de conservação; e (2) Inventário do Acervo Cartográfico do MCR, realizado com recursos do Funcultura/Secretaria de Cultura de Pernambuco em 2013-2014, possibilitando o inventário de todos os itens da coleção, sua catalogação, reprodução fotográfica e digitalização. Mais informações em: <https://issuu.com/josivanrodrigues/docs/inventario-cartografia-mcr>

Anais do 9ำ Congresso Internacional de Design da Informação | CIDI 2019

Proceedings of the 9th Information Design International Conference

Anais do $9^{\circ}$ Congresso Nacional de Iniciação Científica em Design da Informação | CONGIC 2019

Proceedings of the $9^{\text {th }}$ Information Design Student Conference 
A priori, para verificação das representações gráficas da paisagem dos arrecifes na Cartografia MCR, procedemos com a observação de cada um dos seus subconjuntos, buscando verificar tais ocorrências. Desses oito subconjuntos, cinco apresentam representações dos arrecifes (quadro 2): Gravuras, onde temos desenhos, litogravuras, mapas turísticos, reproduções de pinturas etc.; Aerofotogrametria, composto por imagens produzidas na década de 1970 por Serviços Aerofotogramétricos Cruzeiro do Sul S. A.; Projetos Urbanísticos, conjunto formado por documentos que mostram propostas de intervenção no espaço urbano; Documentos Oficiais; e Mapas e Cartas, no qual nos deteremos a seguir e onde encontraremos mapas e plantas da cidade, do porto, de bairros, mapas topográficos, planos topo-hidrográficos, entre outros documentos.

Quadro 2: Ocorrência das representações dos arrecifes na coleção Cartografia MCR por subconjunto. (Fonte: autor).

\begin{tabular}{l|r|r|r|r} 
Subconjunto & $\begin{array}{r}\text { Quantidade } \\
\text { de itens }\end{array}$ & $\begin{array}{r}\text { Quantidade } \\
\text { de ocorrências }\end{array}$ & $\begin{array}{r}\text { Quantidade } \\
\text { de originais }\end{array}$ & $\begin{array}{r}\text { Quantidade } \\
\text { de duplicatas }\end{array}$ \\
\hline Mapas e Cartas & 948 & 201 & 90 & 111 \\
\hline Gravuras & 275 & 34 & 15 & 13 \\
\hline Aerofotogrametria & 219 & 15 & 7 & 0 \\
\hline Projetos urbanísticos & 154 & 7 & 0 & 0 \\
\hline Projetos arquitetônicos & 139 & 0 & 0 & 0 \\
\hline Projetos de mobiliário & 113 & 0 & 1 & 0 \\
\hline Documentos Oficiais & 37 & 1 & 0 & 0 \\
\hline Tipografia & 12 & 0 & 0 & $\mathbf{1 3 4}$ \\
\hline Sem catalogação & 1.898 & $\mathbf{2 5 8}$ & $\mathbf{1 2 4}$ \\
\hline TOTAL & $\mathbf{1 . 8 9}$ & 0 & 0 & 0 \\
\hline
\end{tabular}

* uma das peças não pode ser catalogada devido ao seu estado de conservação.

\section{Um olhar sobre mapas, cartas e a paisagem dos arrecifes}

O acesso aos documentos se fez por meio das matrizes fotográficas digitais em alta resolução obtidas no processo de digitalização do acervo, o que evitou o manuseio dos originais, sem prejuízo da observação pormenorizada das peças, realizada por meio de software para edição e catalogação de imagens (Adobe Photoshop Lightroom 5). Também foram consultados 0 Relatório do Projeto Inventário do Acervo Cartográfico do MCR e as fichas catalográficas da coleção produzidas pela equipe do museu para verificação de informações.

Para uma análise pormenorizada da representação gráfica da paisagem dos arrecifes, foram selecionados quatro espécimes de plantas da cidade do Recife produzidas entre os séculos XVII e XX: (a) "Planta da Cidade do Recife e seus Subúrbios" (figura 3); (b) "Planta Genográfica da Villa de Santo Antônio do Recife de Pernambuco cituada em..." (figura 4); (c) "Planta da Cidade do Recife e seus Arrebaldes" (figura 5); e, (d) "Planta da Cidade do Recife" (figura 6), descritas a seguir.

(a) "Planta da Cidade do Recife e seus Subúrbios" (1645), copiada de outra reprodução de 1913, a partir de publicação de 1645 de Barleus, apresenta a cidade com as benfeitorias do governo Nassau, notadamente as ocupações da llha Antônio Vaz e do que viria a ser o bairro do Recife, com seus traçados, fortificações, diques, canais, pontes, povoações etc. (figura 3). À direita da peça, uma lista de referências com título "Explicações da Planta" enumera 35 pontos de interesse. Os arrecifes são representados em seu trecho norte por uma linha de pedras com 
Rodrigues, J. \& Coutinho, S. G. | O Recife da Cidade: representações de uma paisagem fundacional em artefatos gráficos do acervo cartográfico do Museu da Cidade do Recife

aspecto de rosário, onde vemos registrados o Forte do Picão (ref. 21 - Forte do mar) e a Barreta das Jangadas.

Figura 3: "Planta da Cidade do Recife e seus Subúrbios". Cópia em nanquim de 1985 por Maria de Fátima Malta a partir de cópias da carta de Gaspar Barleus (1645). Acervo do Museu da Cidade do Recife (CT_01109).

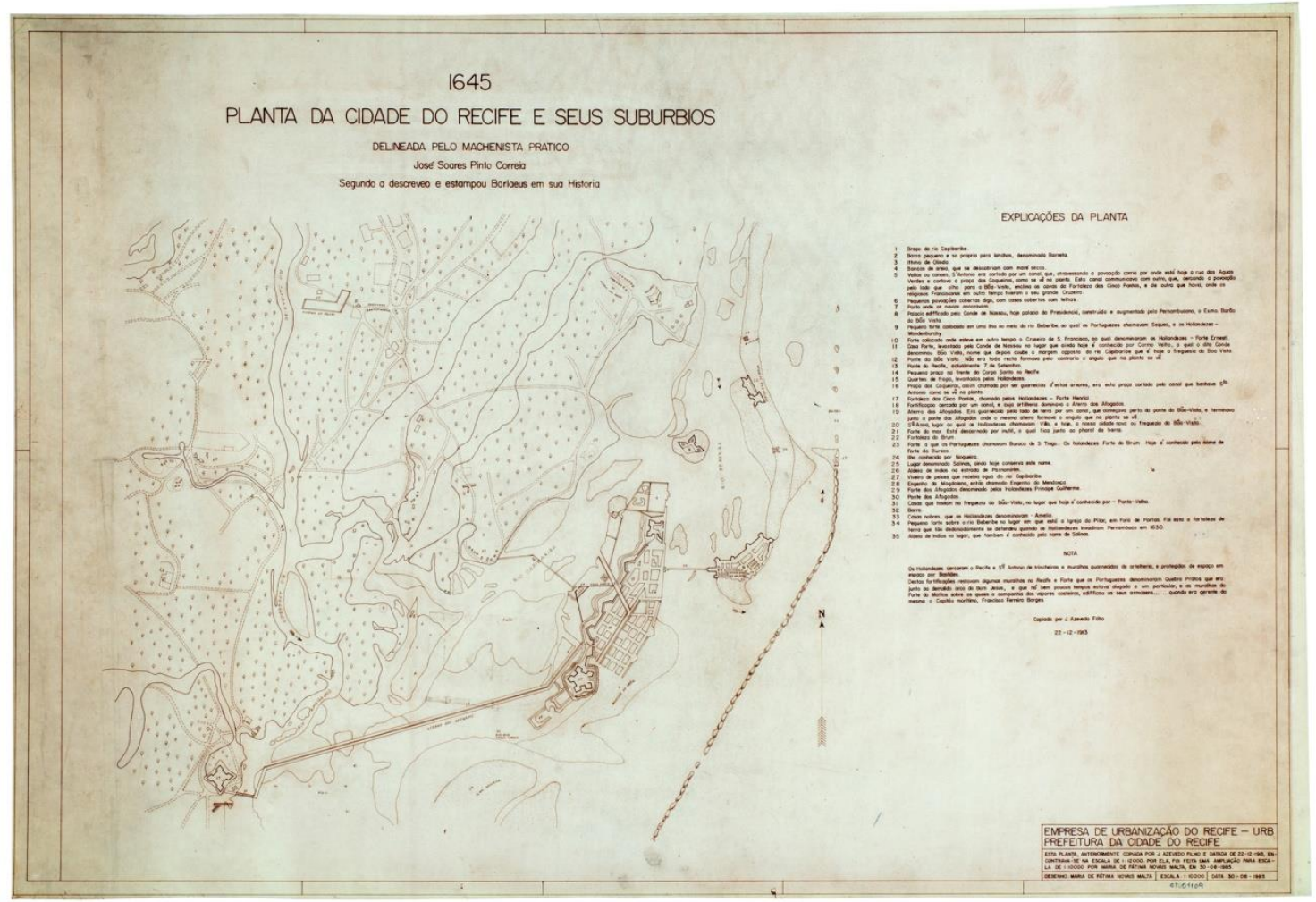

(b) "Planta Genográfica da Villa de Santo Antônio do Recife de Pernambuco..." (1763), cópia feita à mão em 1985 de carta originária da século XVIII, único exemplar do período na coleção. Os arrecifes são representados de forma uniforme e assumem aspecto monolítico. Sobre sua laje, parte superior da estrutura geológica, estão registrados e assinalados a Entrada da Barra, Forte do Picão, Molhe, Barreta das Jangadas e os próprios arrecifes. 
Rodrigues, J. \& Coutinho, S. G. | O Recife da Cidade: representações de uma paisagem fundacional em artefatos gráficos do acervo cartográfico do Museu da Cidade do Recife

Finı ıra 4 - "Planta nennaráfica da Villa de S Antn̂nin dn Rerife " conniada em nannı im de 1985 a nartir de nrininal de

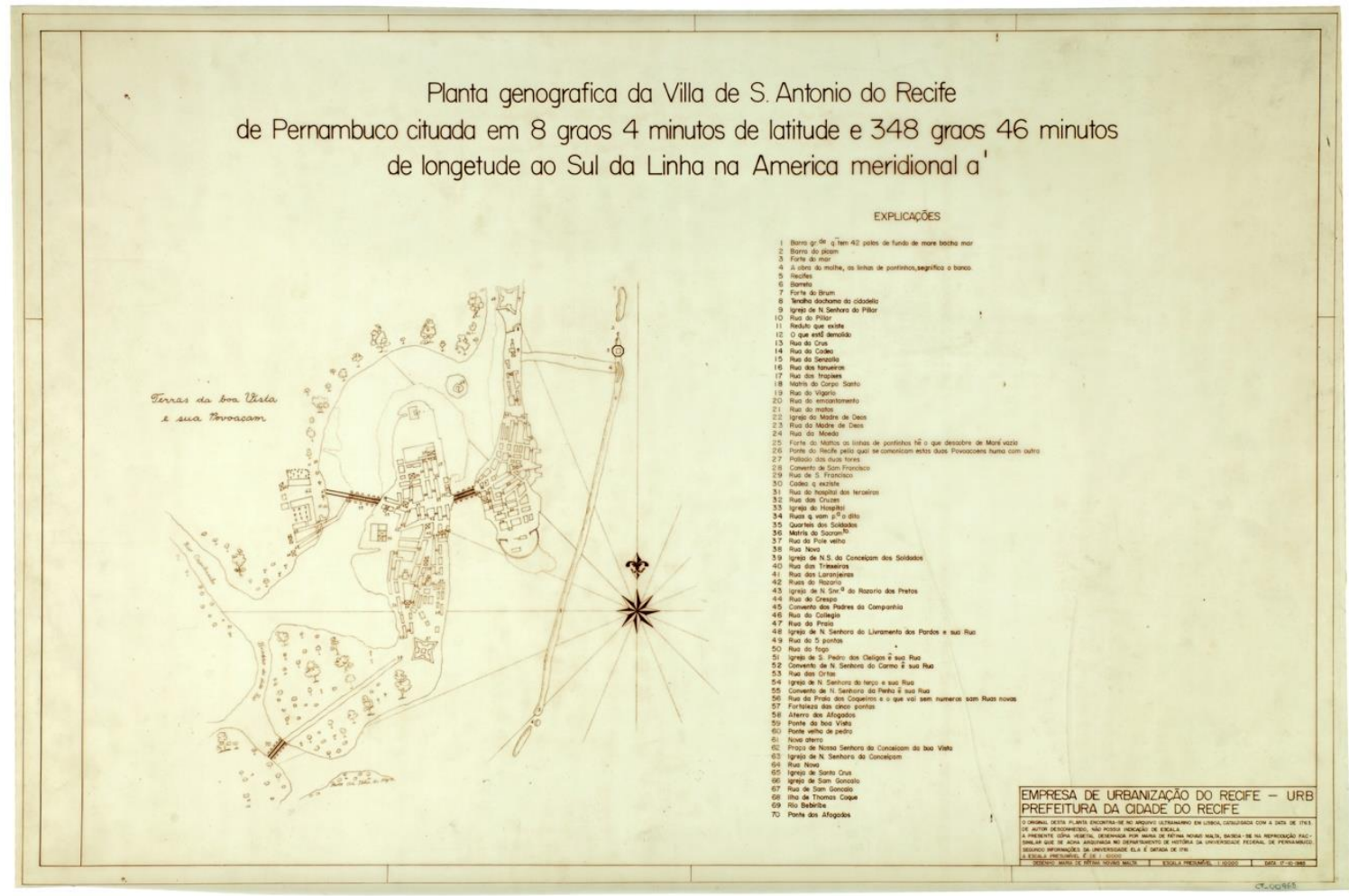

(c) "Planta da Cidade do Recife e seus Arrebaldes" (1885), cópia xerográfica de original datada de 1855, de autoria de loze Mamade Alves Ferreira (figura 5). Apresenta referências com indicação dos principais logradouros dos bairros centrais e edifícios de uso público na parte inferior da carta e no canto superior direito, referências da cidade de Olinda que tem o seu istmo inteiramente representado. Os arrecifes são representados em seu trecho norte até a Ponta do Pina, onde se vê indicados a Entrada da Barra, o Forte do Picão, o Farol e a Barreta das Jangadas. 
Rodrigues, J. \& Coutinho, S. G. | O Recife da Cidade: representações de uma paisagem fundacional em artefatos gráficos do acervo cartográfico do Museu da Cidade do Recife

Figura 5 - "Planta da Cidade do Recife e seus Arrebaldes" (1885), cópia xerográfica. Acervo do Museu da Cidade do Recife (CT_00928).

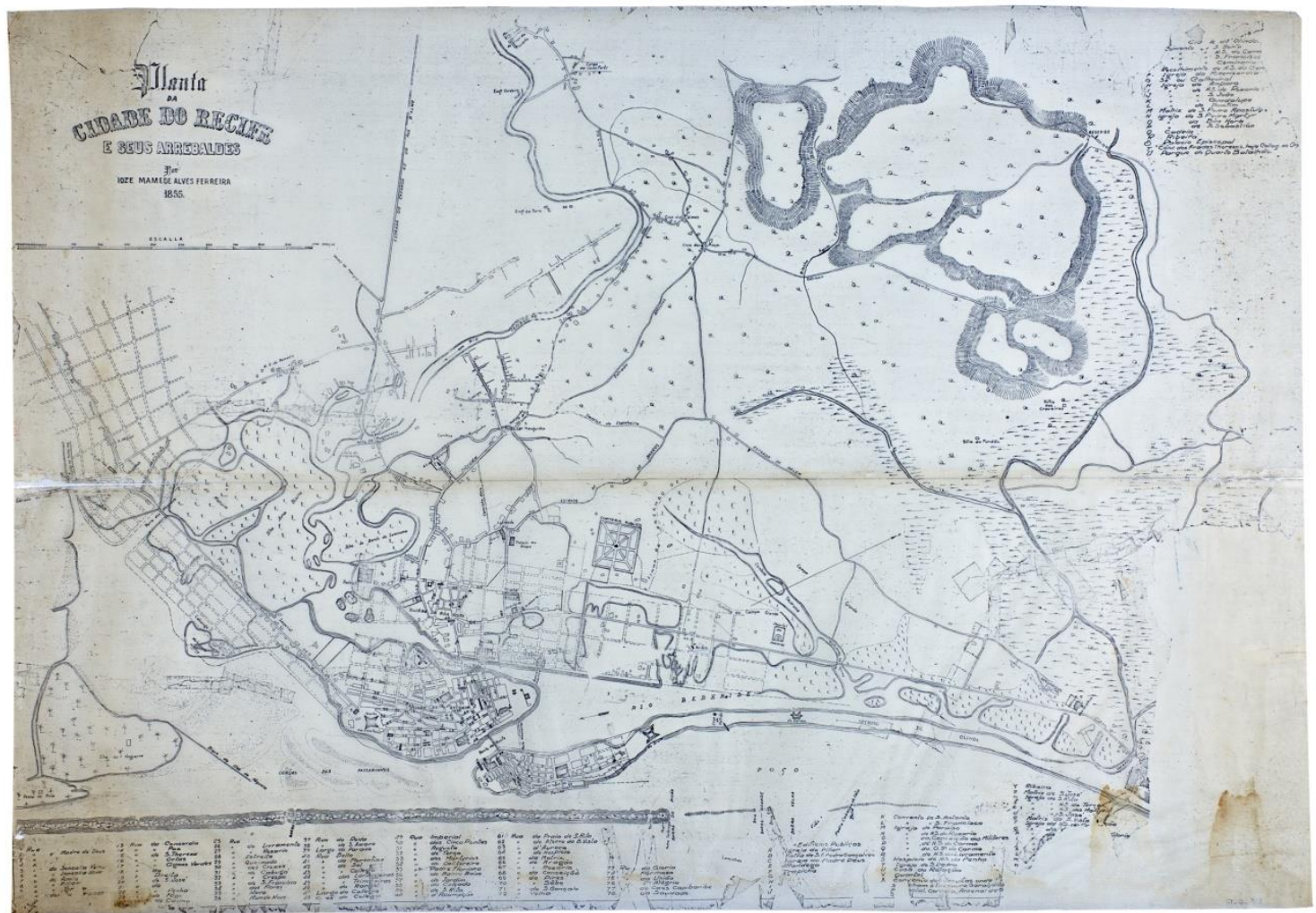

(d) "Planta da Cidade do Recife" (1914), original impresso em cromolitogravura por

Estabelecimento Gráphico Simonek \& Cia., em formato desdobrável, acompanhado de livreto com anúncios publicitários nas primeiras 40 páginas e referências com nomes de ruas, praças e demais logradouros nas últimas 08 páginas (figura 6). O mapa é uma referência para os estudos urbanos do início do século XX e já apresenta o porto e o bairro do Recife com a fisionomia estabelecida com as grandes reformas da área: os armazéns do porto construídos na borda leste do bairro, o novo traçado das ruas e o prolongamento dos arrecifes em concreto para formar a nova entrada da barra. Estão indicados o Farol da Barra, o Forte do Picão e a Casa de Banhos, além do próprio arenito referenciado como Recife. 
Rodrigues, J. \& Coutinho, S. G. | O Recife da Cidade: representações de uma paisagem fundacional em artefatos gráficos do acervo cartográfico do Museu da Cidade do Recife

Figura 6: "Planta da Cidade do Recife" (1914), impresso por Simonek \& Cia, mostrando o novo aspecto dos arrecifes já acrescidos das obras de melhoramento do porto em 1919. Acervo do Museu da Cidade do Recife (CT_00481).

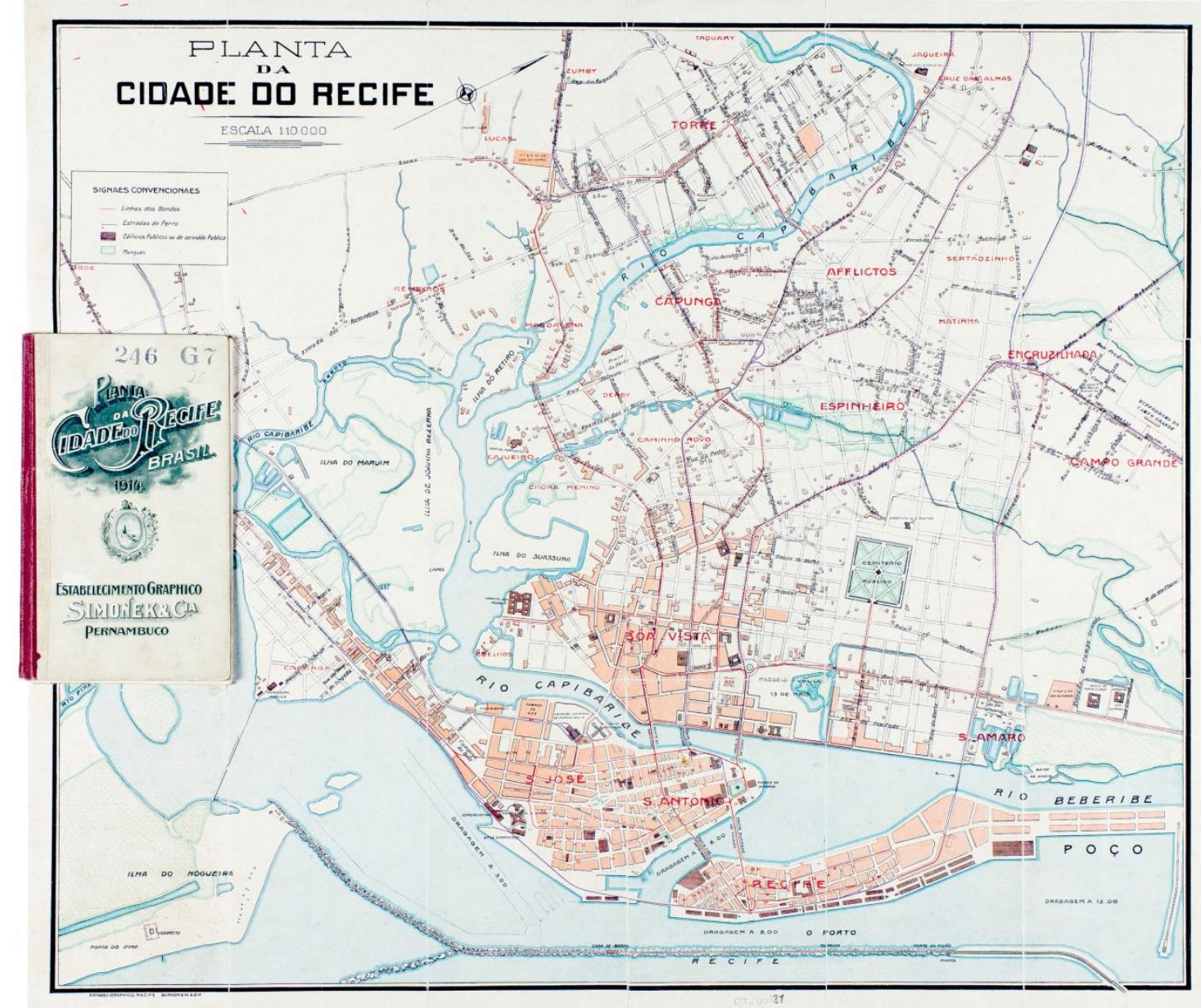

Na busca de identificar, em suas variáveis, mudanças e permanências da paisagem dos arrecifes em diferentes momentos históricos e, consequentemente, distintas tecnologias, formas de elaboração e de produção, elaboramos um quadro de análise comparativo da amostra (quadro 3). 
Rodrigues, J. \& Coutinho, S. G. | O Recife da Cidade: representações de uma paisagem fundacional em artefatos gráficos do acervo cartográfico do Museu da Cidade do Recife

Quadro 3: Quadro de análise das plantas.* (Fonte Autor)

\begin{tabular}{|c|c|c|c|c|}
\hline Espécimes & a & b & c & d \\
\hline Título & $\begin{array}{l}\text { Planta da Cidade do } \\
\text { Recife e seus Subúrbios } \\
\text { (CT_01109) }\end{array}$ & $\begin{array}{l}\text { Planta Genográfica da } \\
\text { Villa de Santo Antônio } \\
\text { do Recife de } \\
\text { Pernambuco cituada } \\
\text { em } 8 \text { graus } 4 \text { minutos } \\
\text { de latitude e } 348 \\
\text { graus } 46 \text { minutos de } \\
\text { longetude ao Sul da } \\
\text { Linha da América } \\
\text { meridional a' } \\
\text { (CT_00965) }\end{array}$ & $\begin{array}{l}\text { Planta } \\
\text { da Cidade do Recife e } \\
\text { seus Arrebaldes } \\
\text { (CT_00928) }\end{array}$ & $\begin{array}{l}\text { Planta da Cidade } \\
\text { do Recife } \\
\text { (CT_00481) }\end{array}$ \\
\hline Subtítulo & $\begin{array}{l}\text { Delineada pelo } \\
\text { machinista prático José } \\
\text { Soares Pinto Correia } \\
\text { segundo a descreveoe } \\
\text { estampou Barlaeus em } \\
\text { sua história. }\end{array}$ & - & - & - \\
\hline Ano & $1645 / ? / 1913 / 1985$ & $1761-1763(?) / 1985$ & $\begin{array}{l}1855 \text { (referente à } \\
\text { original) }\end{array}$ & 1914 \\
\hline $\begin{array}{l}\text { Origem } \\
\text { (cópia / } \\
\text { original) }\end{array}$ & Cópia feita à mão & Cópia feita à mão & Cópia xerográfica & Original \\
\hline Autoria & $\begin{array}{l}\text { Barlaeus (1645)/José } \\
\text { Soares Pinto Correia (?) } \\
\text { /J. Azevedo Filho } \\
\text { (1913)/Maria de Fátima } \\
\text { Malta (1985). }\end{array}$ & $\begin{array}{l}\text { Não indicada (1761 ou } \\
\text { 1763)/Maria de } \\
\text { Fátima Malta (1985). }\end{array}$ & $\begin{array}{l}\text { loze Mamede Alves } \\
\text { Ferreira. }\end{array}$ & $\begin{array}{l}\text { Não indicada* } \\
\text { *A planta parece } \\
\text { ser uma atualização } \\
\text { da de } 1907 \text {, em que } \\
\text { constaem seu } \\
\text { subtítulo a seguinte } \\
\text { informação: } \\
\text { "Reduzida dos } \\
\text { levantamentos da } \\
\text { cidadefeitos por Sir } \\
\text { Douglas Foxe } \\
\text { sócios \& H. Michell } \\
\text { Whitley, membros } \\
\text { do instituto de } \\
\text { Enginheiros Civis } \\
\text { de Londres, } 1906 \text {. }\end{array}$ \\
\hline $\begin{array}{l}\text { Dimensões } \\
\text { (largurax } \\
\text { altura) }\end{array}$ & $99 \times 68 \mathrm{~cm}$ & $81 \times 53 \mathrm{~cm}$ & $\begin{array}{l}108 \times 73 \mathrm{~cm} \\
\text { (Borda inferior direita } \\
\text { danificada) }\end{array}$ & $\begin{array}{l}58 \times 68 \mathrm{~cm} \\
\text { (mapa des dobrável } \\
\text { com livreto de } 48 \\
\text { páginas }(10 \times 20 \mathrm{~cm}) \\
\text { onde constam as } \\
\text { referências da carta } \\
\text { e anúncios } \\
\text { publicitários. }\end{array}$ \\
\hline Escala & $1 / 10.000$ & $1 / 10.000$ (presumida). & $\begin{array}{l}1 / 10.000 \text { (presumida). } \\
\text { Escala gráfica em } \\
\text { braças }\end{array}$ & $1 / 10.000$ \\
\hline
\end{tabular}

Anais do 9 Congresso Internacional de Design da Informação | CIDI 2019 
Rodrigues, J. \& Coutinho, S. G. | O Recife da Cidade: representações de uma paisagem fundacional em artefatos gráficos do acervo cartográfico do Museu da Cidade do Recife

\begin{tabular}{|c|c|c|c|c|}
\hline $\begin{array}{l}\text { Orientação } \\
\text { geográfica }\end{array}$ & $\begin{array}{l}\text { Norte indicado (flectha). } \\
\text { Topo da planta } \\
\text { corres ponde ao Norte. }\end{array}$ & $\begin{array}{l}\text { Norte indicado (rosa } \\
\text { dos ventos). } \\
\text { Topo da planta } \\
\text { corresponde ao Norte. }\end{array}$ & $\begin{array}{l}\text { Não indicada. } \\
\text { Topo da planta } \\
\text { corresponde ao } \\
\text { Oeste. }\end{array}$ & $\begin{array}{l}\begin{array}{l}\text { Norte indicado } \\
\text { (flecha) }\end{array} \\
\text { Topo daplanta } \\
\text { corresponde ao } \\
\text { Oeste. }\end{array}$ \\
\hline Legenda & $\begin{array}{l}\text { Informa sobre anteriores } \\
\text { cópias e mudança de } \\
\text { escala. }\end{array}$ & $\begin{array}{l}\text { Informa sobre } \\
\text { anteriores cópias. }\end{array}$ & - & $\begin{array}{l}\text { Informa "Signaes } \\
\text { convencionaes" } \\
\text { (Linhas dos } \\
\text { Bondes, Estrada de } \\
\text { Ferro, Edificios } \\
\text { Públicos ou de } \\
\text { servidão Pública, } \\
\text { Mangues) }\end{array}$ \\
\hline Referências & $\begin{array}{l}\text { Localizadas na própria } \\
\text { representação } \\
\text { cartográfica è à direita } \\
\text { da carta, em forma de } \\
\text { lista: "Explicaçöes da } \\
\text { planta" (que não fazem } \\
\text { parte da carta original). } \\
\text { Listagem com } 35 \\
\text { referências numeradas } \\
\text { (porto, rio, canais, } \\
\text { pontes, povoaçôes, } \\
\text { fortificações, } \\
\text { logradouros etc.); } \\
\text { "Nota" com informaçôes } \\
\text { sobre vestígios de } \\
\text { fortificações. }\end{array}$ & $\begin{array}{l}\text { Posicionadas à direita, } \\
\text { em forma de lista: } \\
\text { "Explicações". } \\
\text { Listagem com } 70 \\
\text { referếncias ( } 28 \text { ruas e } \\
01 \text { praça) } \\
\text { Constam as sinalados } \\
\text { na representação } \\
\text { cartográfica: "Terras } \\
\text { da boa Vista e sua } \\
\text { Povoaçam"," "Rio } \\
\text { Capibaribe","Brasso } \\
\text { do dito Rio" e"Parte } \\
\text { da llha do Nogueira" }\end{array}$ & $\begin{array}{l}\text { Localizadas na própria } \\
\text { representação } \\
\text { cartográfica, na parte } \\
\text { inferior e no canto } \\
\text { superior direito da } \\
\text { carta, na forma de } \\
\text { lista em colunas. } \\
\text { Listagem com } \\
\text { referếncias } \\
\text { numeradas dos } \\
\text { logradouros ( } 78 \text { ) e de } \\
\text { "Edificios públicos" } \\
\text { (32) }\end{array}$ & $\begin{array}{l}\text { Localizadas na } \\
\text { própria } \\
\text { representação } \\
\text { cartográfica eà } \\
\text { esquerda, em } \\
\text { livreto (10x20cm) } \\
\text { de } 48 \text { páginas } \\
\text { colado à carta com } \\
\text { índicedos } \\
\text { logradouros dos } \\
\text { bairros centrais } \\
\text { (Recife, } 43 \text {, Sto } \\
\text { Antônio e S José, } \\
82, \text { Boa Vista, } 44, \\
\text { total de 169) e } \\
\text { prédios públicos } \\
\text { (79). }\end{array}$ \\
\hline $\begin{array}{l}\text { Trecho } \\
\text { representado } \\
\text { dos arrecifes } \\
\text { (norte/sul) }\end{array}$ & $\begin{array}{l}\text { Norte, entre a entrada } \\
\text { da barra e antiga llha do } \\
\text { Nogueira (Pina), } \\
\text { passando pela Barreta } \\
\text { das Jangadas. }\end{array}$ & $\begin{array}{l}\text { Norte, entre a entrada } \\
\text { da barra e Barreta das } \\
\text { Jangadas). }\end{array}$ & $\begin{array}{l}\text { Norte, entre a entrada } \\
\text { da barra e a Ponta do } \\
\text { Pina, passando pela } \\
\text { Barreta das Jangadas. }\end{array}$ & $\begin{array}{l}\text { Norte, entre a } \\
\text { entrada da nova } \\
\text { barra e antiga llha } \\
\text { do Nogueira (Pina), } \\
\text { passando pela } \\
\text { antiga Barreta das } \\
\text { Jangadas } \\
\text { (fechada), onde } \\
\text { bifurca para se } \\
\text { conectar ao Dique } \\
\text { do Nogueira e } \\
\text { seguir pelo trecho } \\
\text { sul. }\end{array}$ \\
\hline $\begin{array}{l}\text { Representação } \\
\text { gráfica dos } \\
\text { arrecifes }\end{array}$ & $\begin{array}{l}\text { Pedras de tamanhos } \\
\text { regulares justapostas } \\
\text { em linha (forma de } \\
\text { rosário) com } \\
\text { interrupçóes próxima ao } \\
\text { Forte do Picấo e na } \\
\text { Barreta das Jangadas; }\end{array}$ & $\begin{array}{l}\text { Representação } \\
\text { uniforme de aparência } \\
\text { monolitica (laje)com } \\
\text { interrupçôes na } \\
\text { Entrada da barra e na } \\
\text { Barreta das Jangadas; }\end{array}$ & $\begin{array}{l}\text { Pedras em tamanhos } \\
\text { variados aglomeradas } \\
\text { compondo a linha dos } \\
\text { arrecifes, com } \\
\text { interrupção na Barreta } \\
\text { das Jangadas; }\end{array}$ & $\begin{array}{l}\text { Pedras em } \\
\text { tamanhos variados } \\
\text { aglomeradas } \\
\text { compondo a linha } \\
\text { dos arrecifes } \\
\text { (aspecto compacto) } \\
\text { ligado ao Dique do } \\
\text { Nogueira. Trecho } \\
\text { acrescido da nova } \\
\text { barra em concreto } \\
\text { representado } \\
\text { uniformemente, } \\
\text { ultrapassando as } \\
\text { margens da carta. }\end{array}$ \\
\hline
\end{tabular}

Anais do 9 Congresso Internacional de Design da Informação | CIDI 2019

Proceedings of the 9th Information Design International Conference

Anais do $9^{\circ}$ Congresso Nacional de Iniciação Científica em Design da Informação | CONGIC 2019

Proceedings of the $9^{\text {th }}$ Information Design Student Conference 
Rodrigues, J. \& Coutinho, S. G. | O Recife da Cidade: representações de uma paisagem fundacional em artefatos gráficos do acervo cartográfico do Museu da Cidade do Recife

\begin{tabular}{|c|c|c|c|c|}
\hline & $\begin{array}{l}\text { A volumetria das pedras } \\
\text { é obtida com uso de } \\
\text { linhas hachuradas. }\end{array}$ & $\begin{array}{l}\text { A volumetria das } \\
\text { pedras é obtida com } \\
\text { uso de linhas } \\
\text { hachuradas no lado } \\
\text { interno dos arrecifes. }\end{array}$ & $\begin{array}{l}\text { Avolumetria das } \\
\text { pedras é dada com } \\
\text { uso de linhas ezonas } \\
\text { mais escuras. } \\
\text { Area sob influëncia } \\
\text { das marés é indicada } \\
\text { com linhas de } \\
\text { contorno. }\end{array}$ & $\begin{array}{l}\text { Faixa centralizada } \\
\text { sobre o arrecife em } \\
\text { toda sua extensão, } \\
\text { indicando via } \\
\text { construída para a } \\
\text { reforma de } 1909 \text {. } \\
\text { A volumetria das } \\
\text { pedras é dada com } \\
\text { uso de linhase } \\
\text { zonas mais } \\
\text { escuras. } \\
\text { Area sobinfluëncia } \\
\text { das marés é } \\
\text { indicada com zona } \\
\text { de tom azul ao } \\
\text { redor dos arrecifes. }\end{array}$ \\
\hline $\begin{array}{l}\text { Representação } \\
\text { da paisagem } \\
\text { dos arrecifes }\end{array}$ & $\begin{array}{l}\text { Entrada da Barra/Forte } \\
\text { do Picão } \\
\text { (ref. } 21 \text { - Forte do mar); } \\
\text { Barreta das Jangadas } \\
\text { (s/ref.). }\end{array}$ & $\begin{array}{l}\text { Entrada da } \\
\text { Barra/Forte do Picão } \\
\text { (ref. 2-Barra do } \\
\text { Picam e ref. 3 - Forte } \\
\text { do mar); } \\
\text { Molhe } \\
\text { (ref. 4-Obra do } \\
\text { molhe); } \\
\text { Arrecifes } \\
\text { (ref. 5-Recifes } \\
\text { [assinalado em três } \\
\text { pontos diferentes) } \\
\text { Barreta das } \\
\text { Jangadas } \\
\text { (ref. 6-Barreta) }\end{array}$ & $\begin{array}{l}\begin{array}{l}\text { Entrada da Barra } \\
\text { (ref. Barra do Picão); }\end{array} \\
\begin{array}{l}\text { Forte do Picão } \\
\text { (ref. Forte); }\end{array} \\
\text { Farol } \\
\text { (ref. Pharol); } \\
\text { Barreta das } \\
\text { Jangadas } \\
\text { (ref. Barreta). }\end{array}$ & $\begin{array}{l}\text { Nova Entrada da } \\
\text { Barra } \\
\text { ( } \mathrm{s} / \text { ref.); } \\
\text { Antiga Entrada da } \\
\text { Barra } \\
\text { (ref. Pharol e ref. } \\
\text { Forte do Picão); } \\
\text { Molhe } \\
\text { (ref. Muralha) } \\
\text { Arrecifes* } \\
\text { (ref. Recife); } \\
\text { Casa de Banhos } \\
\text { (ref. Casa de } \\
\text { Banhos); } \\
\text { *Os arrecifes } \\
\text { também aparecem } \\
\text { estampados na } \\
\text { capa do livreto que } \\
\text { acompanha a carta, } \\
\text { no brasão do } \\
\text { estado de } \\
\text { Pernambuco, onde } \\
\text { aparece junto ao } \\
\text { Farol e Forte do } \\
\text { Picão. }\end{array}$ \\
\hline
\end{tabular}

*Mantém grafia original nas transcrições.

Nos documentos que integram Mapas e Cartas/Cartografia MCR, formado por 948 itens, temos 201 ocorrências da paisagem dos arrecifes, onde 90 se dão em peças originais (ou reproduções destas), datadas ou originadas dos séculos XVII, XVIII, XIX e XX, respectivamente, 05, 01, 16 e 59 dessas, além de 09 outros artefatos cujas datas não foram identificadas. Os demais 111 documentos foram identificados como duplicatas. São variadas técnicas de representação cartográfica em diversos tipos de produção: desenhos a grafite e nanquim; litografias; cópias feitas à mão, heliográficas e xerográficas; e impressões offset. Mostram a evolução da cidade, do fazer cartográfico e da produção gráfica.

Os quatro espécimes analisados apresentam a representação do trecho norte dos arrecifes, compreendido entre a Entrada da Barra e a Ponta do Pina, como acontece com a maioria dos itens do subconjunto Mapas e Cartas onde a estrutura se faz presente com 74 ocorrências da porção norte para 6 do trecho sul, além de 10 mapas em que temos os dois segmentos representados. Reforça-se, assim, o caráter histórico do trecho norte da rocha, vinculado ao 
ancoradouro e à gênese da cidade. Apenas no século $X X$ que a parte sul passa a figurar nas representações cartográficas, fruto da consolidação da ocupação daquela região, associando àquela faceta da paisagem um uso voltado ao lazer.

Basicamente são três formas de representação dos arrecifes utilizadas nas peças analisadas. A 'carta a' mostra um cordão de pedras de tamanhos regulares, justapostas em linha no formato de um rosário de contas; na carta 'b', os arrecifes aparece com aspecto , representando a laje da rocha; já as cartas ' $c$ ' e 'd' mostram pedras de tamanhos variados, adensadas, para compor a linha do arenito. A carta 'd' mostra o acidente geográfico após as reformas do porto de 1909, quando recebe uma via de acesso sobre sua estrutura, interligando-o ao Dique do Nogueira, e é ampliado para criação da nova barra. Para realização das obras, o Forte do Picão, um importante elemento da paisagem datado de 1610, foi destruído.

Compreendendo os arrecifes como uma paisagem multifacetada, formada por recortes parcelares, a análise das cartas mostra como se apresentam os elementos de composição desses múltiplos enquadramentos. Consideremos aqui, além do elemento geológico em si, as intervenções e as interpretações que se dão sobre a sua estrutura. Todas as cartas apresentam a Entrada da Barra, até o século XIX entendida como entrada da cidade-porto, como uma das representações da paisagem dos arrecifes, seja relacionado-a ao Forte do Picão (cartas 'a', 'b', 'c' e 'd') ou o Farol (cartas 'c' e 'd'). A Barreta das Jangadas, falha por onde passavam pequenas embarcações na altura do Forte das Cinco Pontas, uma outra faceta da paisagem dos arrecifes, aparece nas três primeiras cartas. As cartas 'b' e 'd' são as únicas a assinalar a estrutura dos arrecifes em si, assim como o Molhe, construído próximo ao Forte do Picão do século XVII. A Casa de Banhos, construída sobre a rocha praial no final do século XIX, é um dos elementos de composição da paisagem que aparece na carta 'd' de 1914.

\section{Considerações Finais}

Das muitas paisagens que oferece a "cidade anfíbia", a paisagem dos arrecifes se mostra intimamente ligada à sua gênese. $O$ cinturão de pedras que possibilitou um ancoradouro natural no istmo de Olinda constitui um elemento identitário, relacionando-se diretamente com o mito de fundação da cidade e auxiliando na formação do solo da sua planície. As atividades portuárias ali estabelecidas possibilitaram a criação de uma nova centralidade que passa a figurar como capital da então província no século XIX.

Ao longo dos séculos, a estrutura dos arrecifes passou por transformações operadas pela natureza e pelo homem, confirmando o caráter híbrido dessa paisagem que deve ser interpretada enquanto materialidade e em suas dimensões subjetivas de forma interdependente. Entender como uma paisagem evolui em sua morfologia e na sua relação com a sociedade permite compreender os sujeitos que a modelam, bem como as representações que dela fazem, refletindo a história e a cultura de determinados grupos. Assim, tanto quanto a paisagem, suas representações nos falam da dinâmica envolvida entre natura, sociedade e cultura.

Oficialmente, o arenito consta nos brasões do município do Recife e do Estado de Pernambuco, ainda que o protagonismo seja dado a outros elementos constantes no emblema, como o Forte do Picão, o Farol do Recife, as águas do porto e do mar, a cidade de Olinda e outros recursos da heráldica. Todavia, um esforço pertinente seria o de entender as questões que operam, e de que forma, para que os arrecifes sejam percebidos em seus aspectos simbólicos junto à sociedade.

Mapear e compreender as representações da paisagem dos arrecifes nas demais coleções do MCR, assim como em outras instituições empenhadas em guardar esta tipologia de documento, é de suma importância para fortalecer vínculos de pertencimento com a cidade, haja vista os inquestionáveis valores históricos, sociais e culturais desta paisagem. Esforços no 
Rodrigues, J. \& Coutinho, S. G. | O Recife da Cidade: representações de uma paisagem fundacional em artefatos gráficos do acervo cartográfico do Museu da Cidade do Recife

sentido de visibilizar tal paisagem e suas históricas e atuais representações também se mostram pertinentes.

\section{Referências}

Barreto, A. M. F., Assis, H. M. B., Bezerra, F. H. R., \& Suguio, K. (2010). Arrecifes, a Calçada do Mar de Recife, PE - Importante registro holocênico de nível relativo do mar acima do atual. In: Winge, M.; Schobbenhaus, C.; Souza, D. R. G.; Fernandes, A. C. S.; BerbertBorn, M.; Sallun, Filho, W.; \& Queiroz, E. T. (Eds.) Sítios Geológicos e Paleontológicos do Brasil. Publicado na Internet em 27/10/2010 no endereço http://www.unb.br/ig/sigep/sitio040/sitio040.pdf

Branner, J. C. (1904). The stone reefs of Brazil their geological and geographical relations with a chapter on the coral reefs. Museum of Comparative Zoology, Bull., Harvard College, Cambridge, v.44 (geol.ser.n.7).

Castro, J. de. (1959, [2013]). Um ensaio de geografia urbana: a cidade do Recife (edição alusiva aos 40 anos de falecimento do autor). Recife: Editora Massangana.

Da Silva, V. P. (2007). Paisagem: concepções, aspectos morfológicos e significados. Sociedade \& Natureza, 19(1), junho, 2007, pp. 199-215: [Data de consulta: 12 de fevereiro de 2019] Disponível em:

<http://www.redalyc.org/articulo.oa?id=321327190015> ISSN 0103-1570

Fonseca, H. (2009). Pernambucânia: o que há nos nomes das nossas cidades. Recife: Cepe Editora, 2a Ed.

Gonçalves, F. C., Cardoso, F., Mendes, L., Carneiro, A. R., \& Veras, L. M. (2017). Onde o mar se arrebenta nasce uma paisagem: Recife, a Calçada do Mar. Revista Do Programa De Pós-Graduação Em Arquitetura E Urbanismo Da FAUUSP. São Paulo, 24(43), pp. 144160. Disponível em: <http://www.revistas.usp.br/posfau/article/view/114212>

Maior, M. S., \& Silva, L. D. (1992). O Recife: quatro séculos de sua paisagem. Recife: Editora Massangana.

Meneses, U. T. B. de. (2002). A paisagem como fato cultural. In: YÁZIGI, Eduardo (Org.). Turismo e paisagem. São Paulo: Editora Contexto, pp. 29-64.

\section{Sobre os autores}

Josivan Rodrigues, Mestrando, UFPE, Brasil < prezadojota@gmail.com> Solange Galvão Coutinho, PhD, UFPE, Brasil <sol2015ufpe@gamil.com> 